\title{
ANALISIS KEBUTUHAN MANAJEMEN PENGETAHUAN PADA PERUSAHAAN PERBANKAN
}

\author{
Saide $^{1)}$, Nesdi Evrilyan Rozanda ${ }^{2)}$ \\ ${ }^{1}$ Jurusan Sistem Informasi, Fakultas Teknologi Informasi, Institut Teknologi Sepuluh Nopember \\ Kampus Keputih, Sukolilo Surabaya 60111 \\ Telp: (031) 5999944, Fax: (031) 5964965 \\ ${ }^{2}$ Jurusan Sistem Informasi, Fakultas Sains dan Teknologi, \\ Universitas Islam Negeri Sultan Syarif Kasim Riau \\ E-mail: saidefc@gmail.com
}

\begin{abstract}
The nature of implicit knowledge in each individual within the company may be lost from PT. Bank Perkreditan Rakyat Tuah Negeri Mandiri Pekanbaru (BPR) due to employees who resign, transfer work, retire first, moving the workers to another company which became competitors even possible tragedy death. The knowledge acquired through learning and experience that is long enough at a company by every individual is incorporated in it as well as a large investment from companies, so if a company loses asset knowledge and experience will be a big loss. The method used collected data in this research is the questionnaire that was distributed to employees, interviews with leaders and observation, then data process using the SPSS. In addition, this paper also uses the framework method Amrit Tiwana, Michael Zack and Nonaka Tekeuchi.
\end{abstract}

\section{Abstrak}

Sifat pengetahuan yang implisit pada setiap individu dalam perusahaan dapat hilang dari lingkungan PT. Bank Perkreditan Rakyat Tuah Negeri Mandiri Pekanbaru (BPR) dikarenakan karyawan yang mengundurkan diri, mutasi kerja, pensiun lebih dulu, pindah kerja ke perusahaan lain yang menjadi kompetitor bahkan mungkin musibah kematian. Pengetahuan diperoleh melalui proses pembelajaran dan pengalaman yang cukup panjang pada suatu perusahaan oleh setiap individu yang tergabung di dalamnya serta investasi besar dari perusahaan, maka jika sebuah perusahaan kehilangan aset pengetahuan dan pengalaman tersebut akan menjadi sebuah kerugian besar. Metode pengumpulan data yang digunakan pada penelitian ini adalah dengan kuisioner yang disebar kepada karyawan, wawancara terhadap pimpinan dan observasi, lalu mengolah data menggunakan SPSS. Selain itu, tulisan ini juga menggunakan metode framework Amrit Tiwana, Michael Zack dan Nonaka Tekeuchi.

Kata kunci: kebutuhan, manajemen pengetahuan, perbankan.

\section{PENDAHULUAN}

Knowledge management (KM) atau manajemen pengetahuan hadir untuk memberikan solusi terhadap permasalahan manajemen lama dalam peningkatan pengetahuan karyawan dan mengkombinasikan antara proses bisnis dengan konsep manajemen pengetahuan yang dirancang. Menurut Nonaka dan Takeuchi (1995) keberhasilan perusahaan Jepang ditentukan oleh keterampilan dan kepakaran mereka dalam penciptaan pengetahuan organisasi. Edmon Dantes selaku pimpinan BPR mangatakan permasalahan yang terjadi pada divisi marketing adalah pengelolaan karyawan yang belum berhasil, masih sering terjadi pengunduran diri karyawan. Knowledge management melihat pengunduran diri dan atau karyawan senior berpengalaman yang pensiun berakibat hilangnya aset pengetahuan dan pengalaman dari karyawan tersebut. Akibat lain yang muncul adalah kurangnya tutor transfer informasi dan pengetahuan antar karyawan terutama bagi karyawan baru. Permasalahan lain adalah tidak dilakukan dokumentasi pengetahuan yang diperoleh ketika pelatihan, seminar dan workshop yang diikuti karyawan dan tidak berbagi pengetahuan tersebut kepada karyawan yang tidak mengikuti pelatihan, serta belum didokumentasikan penyelesaian masalah yang sudah atau belum terjadi alias dikenal juga dengan pengetahuan tersembunyi (terbatinkan). Pengetahuan ini perlu dikonversi menjadi pengetahuan eksplisit (terdokumentasi) agar bisa digunakan bersama dan perlu dilakukan proses eksternalisasi (tacit ke eksplisit). 
Solusi yang ditawarkan adalah perusahaan harus mampu mengelola karyawan dengan serius melalui manajemen aset (pemikiran, pengetahuan dan pengalaman). Kemudian mencari tahu halhal yang sudah diketahui karyawan dan yang belum diketahui karyawan agar nantinya setiap karyawan memiliki kompetensi sesuai yang diharapkan perusahaan. Selain itu, hal lain yang melatar belakangi penelitian ini adalah kebutuhan pentingnya mempertahankan aset pengetahuan, pembelajaran berkelanjutan, serta pengetahuan karyawan yang merupakan aset berharga dan sangat penting bagi perusahaan.

\subsection{Konsep Knowledge}

Para pakar dibidang knoweledge management telah banyak mendefinisakn arti dari knowledge. Secara umum adalah pengetahuan merupakan perpaduan dari pengalaman, nilai, informasi kontektual, pandangan pakar dan intuisi mendasar yang memberikan suatu lingkungan dan kerangka untuk mengevaluasi dan menyatukan pengalaman baru dengan informasi. Diperusahaan, pengetahuan sering terkait tidak hanya dokumen atau tempat penyimpanan barang berharga, tetapi juga dalam rutinitas, proses, praktek dan norma perusahaan (Thomas Devenport dan Laurence, 1998 dikutip oleh yuliazmi, 2005). Berbeda dari data \& informasi, pengetahuan berada pada tingkat tertinggi dalam hierarki dengan informasi di tingkat menengah, dan data berada di tingkat terendah (Nonaka dan Takeuchi, 1995).

Dibedakan pemahaman antara tacit dan eksplicit knowledge, pengetahuan tacit adalah pengetahuan yang masih tersembunyi, masih dibatinkan oleh orang, masih dalam bentuk ide, pemikiran, dan sifatnya masih personal. Sementara itu, pengetahuan ekplisit adalah pengetahuan yang sudah dalam format dokumentasi, sudah direkam dalam berbagai bentuk alat perekam, bisa ditransmisikan, bisa berbagi dan dihitung secara tertentu jika sudah diwadahi dalam bentuk tertentu. Buku, makalah, majalah, rekaman digital, rekaman audio, rekaman di memory card, flast disk, hard disk, dan lain-lain, adalah bentuk-bentuk media untuk menyimpan pengetahuan yang berjenis eksplisit (Pawit, 2012).

\subsection{Konsep Knowledge Management (KM)}

Defenisi tentang KM sangat beragam dan kemungkinan akan bertambah seiring dengan semakin berkembang dan beragamnya pemahaman tentang KM. Defenisi KM menurut Amrit Tiwana (2001) dalam buku yang berjudul The Essential Guide to Knowledge Management,
KM yaitu pengelolaan pengetahuan perusahaan dalam menciptakan nilai bisnis (business value) dan menghasilkan keunggulan kompetitif yang berkesinambungan (sustainable competitive advantage) dengan mengoptimalakan proses penciptaan, komunikasi dan penerapan semua pengetahuan yang dibutuhkan sebagai bagian utama pencapaian tujuan bisnis.

Knowledge management dapat diklasifikasikan berdasarkan dua sisi yaitu secara operasional dan strategis. KM secara operasional merupakan aktifitas perusahaan dimana terjadi pengembangan dan pemanfaatan pengetahuan. Sedangkan KM secara strategis adalah memantapkan perusahaan berbasis pengetahuan. KM pada dasarnya bagaimana cara perusahaan mengelola pengetahuan secara terorganisasi untuk mencapai nilai bisnis dan membangkitkan keuntungan bersaing (Tiwana, 2000). Dalam perusahaan, pengetahuan tidak hanya dokumen atau tempat penyimpanan barang berharga, tetapi juga dalam rutinitas, proses, praktek dan norma perusahaan (Thomas Devenport dan Laurence, 1998 dikutip oleh yuliazmi, 2005). Riset Delphi Group menunjukkan bahwa pengetahuan dalam organisasi tersimpan dalam struktur $42 \%$ dipikiran (otak) karyawan, 26\% dokumen kertas, $20 \%$ dokumen elektronik, $12 \%$ pengetahuan berbasis elektronik. Tujuan penerapan konsep KM adalah untuk meningkatkan dan memperbaiki oprasional perusahaan dalam mencari keuntungan yang lebih baik, lebih berkualitas dan akhirnya lebih kompetitif, terutama jika dibandingkan dengan organisasi sejenis. Kinerja organisasi sebagai hasil proses manajemen pengetahuan akan berbeda dengan kinerja organisasi tanpa memperhatikan intellectual capital (modal intelektual).

\subsection{Metode Knowledge Management}

Manfaat potensial dari strategi-strategi KM dan pengalaman para ahli menunjukkan bahwa banyak organisasi yang masih menghadapi kesulitan dalam menjembatani antara strategi dan praktek. Kesulitan muncul diakibatkan oleh tidak adanya hubungan yang jelas antara strategi KM dan berbagai jenis KMS yang ada. Perusahaan dapat menggunakan kerangka berfikir Zack sebagai alat bantu dalam usaha untuk mengetahui pengetahuan apa yang harus dimiliki dan yang sudah dimiliki. Kerangka berfikir Zack digambarkan sebagai berikut (Tiwana 2000, dikutip oleh Yuliazmi 2005). Gambar 1 memperlihatkan bahwa analisis kesenjangan pengetahuan pada dasarnya merupakan kegiatan yang sulit sekali dipisahkan dari kegiatan penyusunan starategi perusahaan. 


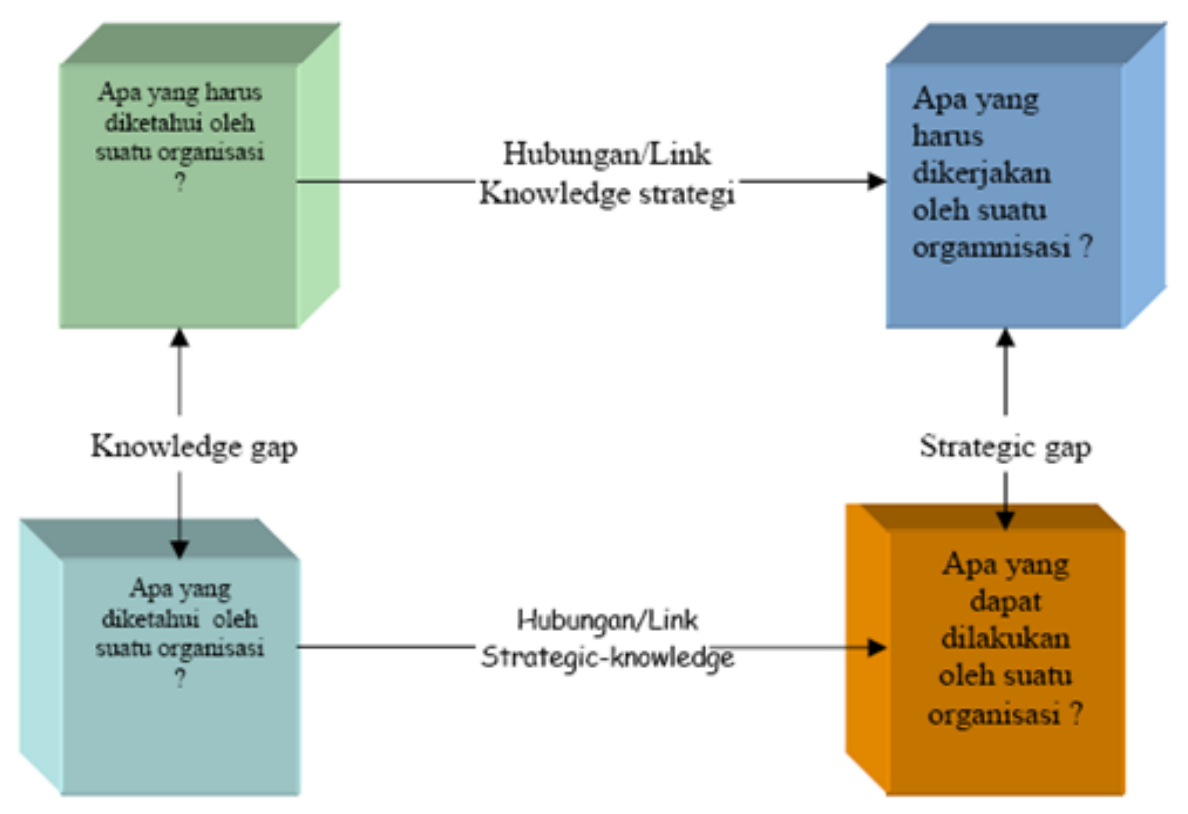

Gambar 1. Pola Hubungan Zack (Tiwana, 2000 dikutip oleh Yuliazmi, 2005)

Selain itu, proses transfer pengetahuan tacit lebih sulit untuk dilakukan dibanding proses transfer pengetahuan eksplisit dan adanya pembagian model konversi pengetahuan menjadi 4 cara (Nonaka dkk 1991, dikutip oleh Yuliazmi 2005):

- Pengetahuan tacit ke pengetahuan eksplisit disebut proses eksternalisasi.

- Pengetahuan tacit ke pengetahuan tacit disebut proses sosialisasi.

- Pengetahuan eksplisit ke pengetahuan eksplisit disebut proses kombinasi.

- Pengetahuan eksplisit ke pengetahuan tacit disebut proses internalisasi.

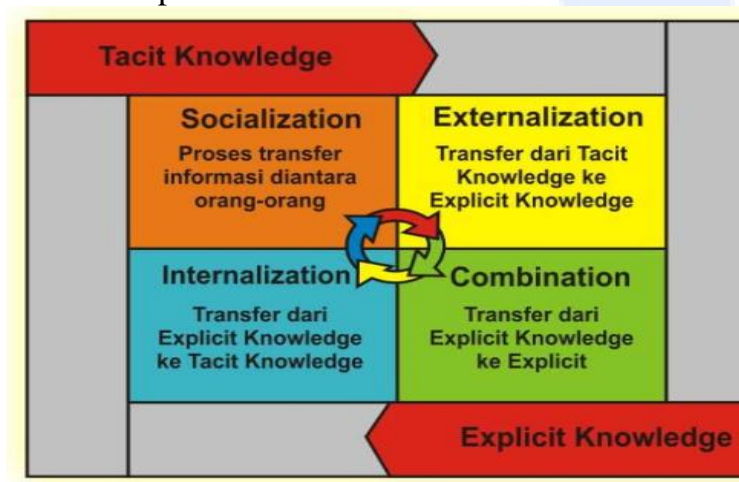

Gambar 2. Model SECI konversi pengetahuan (Nonaka dkk, 1991 dikutip oleh Yuliazmi, 2005)

Beberapa riset terdahulu yang menggunakan metode ini (KM) diantaranya oleh Inyoman Rudo Kurniawan (2010) dengan topik perancangan KMS di SMK Negeri 1 Kotabaru menggunakan metode 10 langkah roadmap Amrit Tiwana. Tujuan dari perancangan KMS untuk menyelesaikan permasalahan terkait adanya guru yang berprestasi dan yang belum, hilangnya pengetahuan sekolah karena guru pindah atau berhenti. Selain itu, studi kasus di Universitas
Bina Nusantara Jakarta (2013) yaitu perancangan prototype KM PT. Orang Tua Group (Divisi Management Automation Information) dengan metode yang sama, namun pada penelitian ini penulis menggunakan hingga langkah ke 7 dari 10 langkah KM Amrit Tiwana. Adapun contoh penelitian KM yang berbeda yaitu pada skripsi Lasma (2009) dengan topik analisis kesenjangan pengetahuan (knowledge gap) karyawan PT. Pelni Persero Direktorat SDM dan Umum menggunakan metode Michael Zack dan skor rataan skala Likert. Tujuannya adalah mengidentifikasi sumber pengetahuan karyawan dan analisis pengetahuan yang diharapkan perusahaan untuk dimiliki karyawan melalui analisis kesenjangan pengetahuan karyawan.

Dari berbagai penelitian terdahulu belum terdapat penulis yang menggunakan beberapa metode sekaligus. Berangkat dari itu, sebagai bentuk temuan baru penulis coba mengkolaborasikan tiga metode sekaligus yakni roadmap Amrit Tiwana, model Michael Zack dan konversi pengetahuan oleh Nonaka dan Takeuchi.

\section{METODOLOGI}

Penulis menggunakan roadmap Amrit Tiwana yang disajikan pada gambar 3 dan model Zack yang disajikan pada gambar 1 dan tabel 1 untuk analisis kesenjangan pengetahuan karyawan dan strategi perusahaan, serta menggunakan model SECI (Nonaka dan Takeuchi) dalam siklus manajemen dan penciptaan pengetahuan yang disajikan pada gambar 2 dan tabel 2 . 


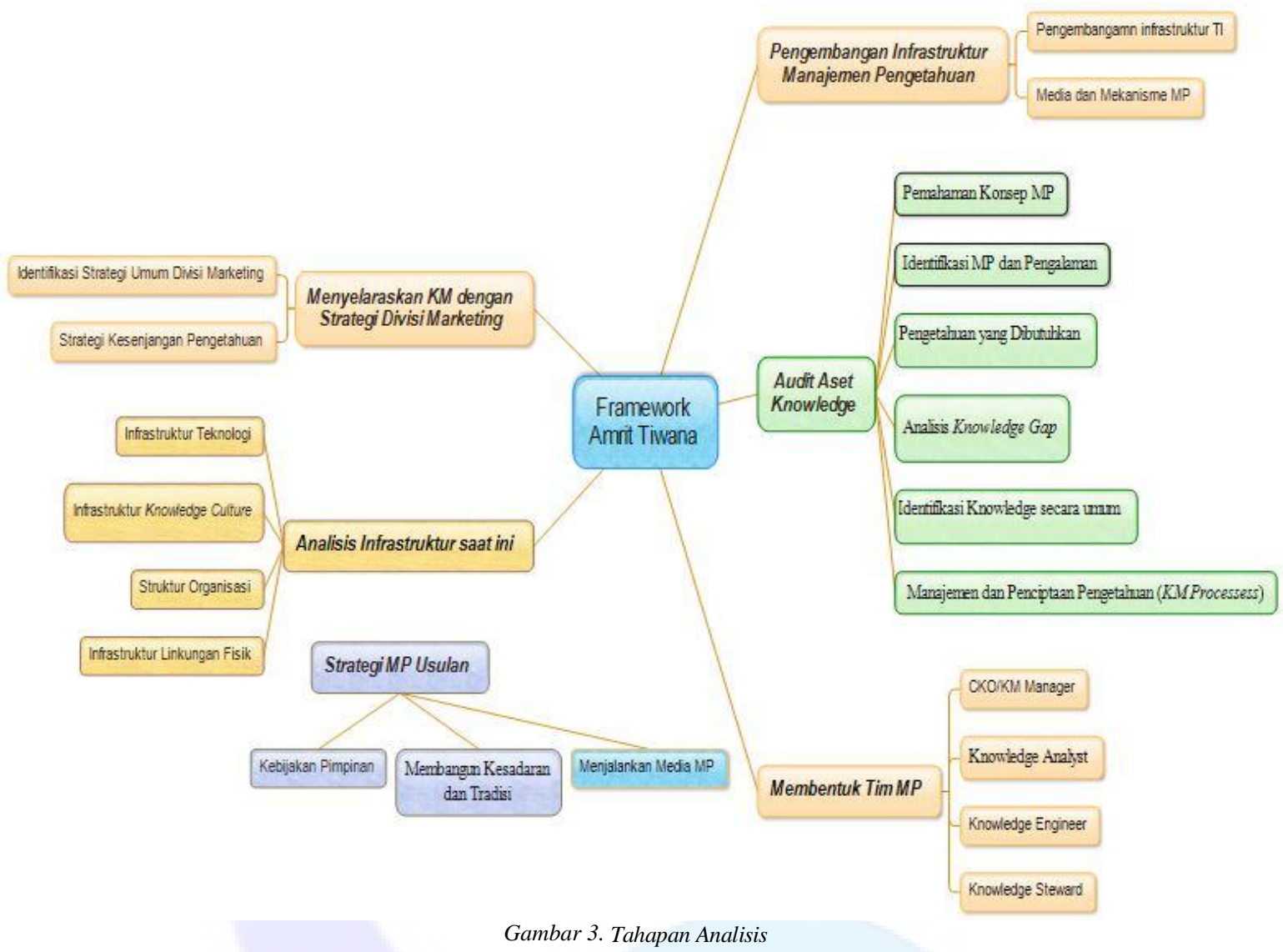

Model Amrit Tiwana digunakan sebagai tahapan utama atau secara keseluruhan pada penelitian ini. Dibeberapa sub tahapan Amirt Tiwana terdapat tahapan menggunakan metode lainnya: pertama, model Michael Zack sebagai metode dalam menyelaraskan strategi divisi marketing dengan strategi pengetahuan yang menggunakan teknik wawancara dan kuisioner, kemudian dilakukan pengolahan data menggunakan software SPSS yang hasilnya disajikan pada tabel 1. Kedua, model SECI (Nonaka dan Takeuchi) yang disajikan pada tabel 2 yakni sabagai metode dalam membuat media, mekanisme dan teknologi yang bisa digunakan program manajemen pengetahuan di BPR.

\section{HASIL DAN PEMBAHASAN}

Topik utama yang manjadi fokus analisis yaitu penyelarasan KM dengan strategi bisnis Divisi Marketing, analisis knowledge gap (kesenjangan pengetahuan) karyawan divisi marketing, manajemen dan proses penciptaan pengetahuan serta media dan mekanisme KM yang bisa difungsikan BPR.

Tabel 1. Penyelarasan KM dengan Strategi BRP (model Zack).

$$
\text { Apa yang }
$$

Divisi Marketing Ketahui

Apa yang dapat
Dilakukan Divisi Marketing

\footnotetext{
1.Penyelesaian kasus masih bersifat tacit, atau 1. Kasus diselesaikan via telepon atau e-mail yang belum terdokumentasi. dikirim kepada staff.

2.Belum diseber dokumen detail uraian tugas 2. Memberikan dokumen tersebut kepada setiap dan fungsi karyawan.

3.Pengunduran kepala divisi untuk diserahkan kepada karyawan. dan penyebabnya.

4. Adanya training (inhouse dan eksternal), seminar, workshop yang diikuti oleh beberapa karyawan BPR .

diri karyawan

5.Tersedia jaringan intranet/internet sebagai media browsing, e-mail, sarana promosi online

3. Mempertahankan asset pengetahuan karyawan

4. Karyawan yang mengikuti training mencatat pengetahuan yang mereka dapatkan pada saat training untuk menambah basis data pengetahuan karyawan dan perusahaan.

5. Jaringan internet digunakan sebagai media peningkatan pengetahuan, sharing knowledge dan untuk melakukan promosi secara online.
} 


\begin{tabular}{|c|c|}
\hline $\begin{array}{c}\text { Apa yang harus } \\
\text { Diketahui Divisi Marketing }\end{array}$ & $\begin{array}{c}\text { Apa yang harus } \\
\text { Dilakukan Divisi Marketing }\end{array}$ \\
\hline $\begin{array}{l}\text { 1.a. Cara menangkap asset pengetahuan (tacit ke } \\
\text { eksplisit dan sebaliknya). } \\
\text { b.Cara membuat penanganan kasus lebih } \\
\text { sistematis dan best practice } \\
\text { 2. Teknik pengolahan, penyimpanan dan } \\
\text { penyebarluasan dokumen menggunakan IT. } \\
\text { 3. Memahami tahapan -tahapan proses KM. } \\
\text { 4. Bagaimana bentuk presentasi dan sharing } \\
\text { knowledge yang efektif. } \\
\text { 5. Bagaimana membuat dan mengoperasikan fitur } \\
\text { serta fungsi web portal KM. }\end{array}$ & $\begin{array}{l}\text { 1. a.Mendokumentasi dan menyebarkan semua } \\
\text { pengetahuan tentang kasus terkait agar dapat } \\
\text { digunakan karyawan. } \\
\text { b.Menyediakan cara penanganan kasus yang } \\
\text { sistematis } \\
\text { 2. Mengolah dan menyebarkan dokumen SOP secara } \\
\text { komputerisasi agar lebih cepat dan efektif. } \\
\text { 3. Melakukan proses dan tahapan KM } \\
\text { 4. Menfasilitasi karyawan yang telah mengikuti } \\
\text { training untutk presentasi sharing pengetahuan } \\
\text { 5. Membuat media dan mekanisme KM }\end{array}$ \\
\hline
\end{tabular}

\subsection{Analisis Knowledge Gap (K-Gap)}

Analisis K-Gap merupakan analisis perbandingan antara tingkat kepentingan terhadap pengetahuan yang dibutuhkan dan tingkat penguasaan karyawan.

\section{a. Pengolahan Data dan Analisis}

Analisa kesenjangan pengetahuan dilakukan untuk mengetahui keadaan pengetahuan yang dibutuhkan dan kondisi pengetahuan yang saat ini. Rumus menghitung rata-rata tingkat kepentingan:

$\mathrm{NKi}=((\mathrm{K} 1 \mathrm{x} 1)+(\mathrm{K} 2 \times 2)+(\mathrm{K} 3 \times 3)+(\mathrm{K} 4 \mathrm{x} 4)) / \mathrm{R}$. Dimana:

- $\mathrm{NKi}=$ Nilai kepentingan terhadap knowledge $\mathrm{i}$

- $\mathrm{K} 1$ = Jumlah responden jawaban "A"

- $\mathrm{K} 2$ = Jumlah responden jawaban "B"

- $\mathrm{K} 3$ = Jumlah responden jawaban " $\mathrm{C}$ "

- $\mathrm{K} 4$ = Jumlah responden jawaban " $\mathrm{D}$ "

- $\mathrm{R}=$ Total responden

Rumus menghitung rata-rata tingkat kepentingan:

$\mathrm{NPi}=((\mathrm{P} 1 \times 1)+(\mathrm{P} 2 \times 2)+(\mathrm{P} 3 \times 3)+(\mathrm{P} 4 \times 4)) / \mathrm{R}$. Dimana:

- NPi = Nilai penguasaan terhadap knowledge $\mathrm{i}$

- P1 = Jumlah responden jawaban " $A$ "

- $\mathrm{P} 2$ = Jumlah responden jawaban "B"

- $\mathrm{R}=$ Total responden

- P3 = Jumlah responden jawaban " $\mathrm{C}$ "

- P4 = Jumlah responden jawaban " $D$ "

- $\mathrm{R}=$ Total respondens

Berikut perbandingan pengetahuan karyawan antara tingkat kepentingan dengan tingkat penguasaan:

\begin{tabular}{|c|c|c|c|c|c|c|c|c|c|c|c|c|}
\hline \multirow{2}{*}{ No } & \multirow{2}{*}{ Knowledge } & \multicolumn{5}{|c|}{ Tingkat Kepentingan } & \multicolumn{5}{|c|}{ Tingkat Penguasaan } & \multirow{2}{*}{$\begin{array}{l}\text { K-Gap } \\
\text { Nki-Npi }\end{array}$} \\
\hline & & 1 & 2 & 3 & 4 & Nki & $A$ & B & C & D & Npi & \\
\hline 1 & Manajemen data nasabah & 0 & 1 & 4 & 1 & 3.00 & 0 & 1 & 4 & 1 & 3.00 & 0.00 \\
\hline 2 & Komunikatif & 0 & 0 & 5 & 1 & 3.17 & 0 & 2 & 3 & 1 & 2.83 & 0.33 \\
\hline 3 & Maintenance Nasabah & 0 & 0 & 4 & 2 & 3.33 & 0 & 2 & 4 & 0 & 2.67 & 0.67 \\
\hline 4 & Funding dan Lending & 0 & 0 & 3 & 3 & 3.50 & 0 & 2 & 4 & 0 & 2.67 & 0.83 \\
\hline 5 & Surveyor & 0 & 0 & 4 & 2 & 3.33 & 0 & 3 & 3 & 0 & 2.50 & 0.83 \\
\hline 6 & Manajemen waktu & 0 & 0 & 4 & 2 & 3.33 & 0 & 2 & 3 & 1 & 2.83 & 0.50 \\
\hline 7 & Kontrol dan Pengawasan & 0 & 1 & 5 & 0 & 2.83 & 0 & 3 & 3 & 0 & 2.50 & 0.33 \\
\hline
\end{tabular}

Gambar 4. Hasil kesenjangan pengetahuan

Keterangan:

Nki = Tingkat kepentingan knowledge $\mathrm{i}$

$\mathrm{Npi}=$ Tingkat penguasaan knowledge $\mathrm{i}$

Terlihat knowledge dengan K-Gap tertinggi yaitu knowledge maintenance of costumer (pengetahuan mempertahankan nasabah), terdapat K-Gap dengan nilai nol, yaitu surveyor knowledge (pengetahuan surveyor), sedangkan knowledge yang lain berada pada kisaran 0,33 hingga 1,00.

b. Pengetahuan wajib dan pilihan

Adapun kriteria yang termasuk dalam knowledge wajib adalah knowledge yang memiliki nilai kepentingan dengan nilai antara 3 sampai 4 dan atau memiliki nilai kesenjangan knowledge tertinggi. Sedangkan knowledge pilihan adalah knowledge dengan nilai kepentingan kurang dari 3 dan selain knowledge dengan nilai kesenjangan tertinggi.

Berdasarkan hasil analisis didapat 6 knowledge wajib untuk peningkatan pengetahuan karyawan dan harus segera dilakukan. Peningkatan dapat melalui training, workshop, seminar dan sebagainya. Knowledge wajib bagi karyawan divisi marketing adalah knowledge komunikatif, maintenance nasabah, funding dan lending (pencarian dan pencairan dana)/ account officer, surveyor, manajemen waktu, kontrol dan pengawasan. Knowledge pilihan bagi karyawan divisi marketing adalah knowledge manajemen basis data. 
Tabel 2. Media, mekanisme dan teknologi yang bisa digunakan manajemen pengetahuan BPR.

\begin{tabular}{|c|c|c|c|c|}
\hline & & KM Sub & & \\
\hline Proses KM & Sistem KM & Proses & Mekanisme KM & Teknologi KM \\
\hline \multirow{4}{*}{$\begin{array}{l}\text { Knowledge } \\
\text { Discovery }\end{array}$} & \multirow{4}{*}{$\begin{array}{l}\text { Knowledge } \\
\text { Discovery } \\
\text { System }\end{array}$} & $\begin{array}{l}\text { Kombinasi } \\
(\mathrm{E}-\mathrm{E})\end{array}$ & $\begin{array}{l}\text { Dokumen, meeting, } \\
\text { sharing session, dokumen } \\
\text { rencana, laporan data } \\
\text { nasabah, buku referensi, } \\
\text { forum diskusi. }\end{array}$ & $\begin{array}{l}\text { Basis data, repository } \\
\text { informasi, web portal, } \\
\text { best practices. }\end{array}$ \\
\hline & & & Percakapan, mentoring/ & Video conferencing, \\
\hline & & & pembinaan dan magang, & electronic dission \\
\hline & & $\begin{array}{l}\text { Sosialisasi } \\
(\mathrm{T}-\mathrm{T})\end{array}$ & $\begin{array}{l}\text { pengamatan, peniruan dan } \\
\text { praktek. Interaksi (antara } \\
\text { pimpinan-pegawai), } \\
\text { pesan singkat. }\end{array}$ & groups, e-mail, telephon. \\
\hline \multirow{4}{*}{$\begin{array}{l}\text { Knowledge } \\
\text { Capture }\end{array}$} & \multirow{4}{*}{$\begin{array}{l}\text { Knowledge } \\
\text { Capture } \\
\text { System }\end{array}$} & $\begin{array}{l}\text { Eksternalisasi } \\
\text { (T-E) }\end{array}$ & $\begin{array}{l}\text { Konversi dari tacit ke } \\
\text { eksplisit, menterjemahkan } \\
\text { tacit dari para ahli, training, } \\
\text { learning by doing, face to } \\
\text { face meetings, pesan singkat, } \\
\text { dokumen pertemuan. }\end{array}$ & $\begin{array}{l}\text { Experts system, chat } \\
\text { groups, best practices, } \\
\text { lessons learned database, } \\
\text { portal. } \\
\end{array}$ \\
\hline & & & & \\
\hline & & & Pelatihan, learning by & Computer-based \\
\hline & & $\begin{array}{l}\text { Internalisasi } \\
(\mathrm{E}-\mathrm{T})\end{array}$ & $\begin{array}{l}\text { (belajar dari pengalaman dan } \\
\text { survey), face to face } \\
\text { meetings, surat edaran, } \\
\text { papan pengumuman. }\end{array}$ & $\begin{array}{l}\text { Computer-based } \\
\text { simulation. }\end{array}$ \\
\hline \multirow{4}{*}{$\begin{array}{l}\text { Knowledge } \\
\text { Sharing }\end{array}$} & \multirow{4}{*}{$\begin{array}{l}\text { Knowledge } \\
\text { Sharing } \\
\text { System }\end{array}$} & & face-to-face $\quad$ meeting & Video conferencing, \\
\hline & & $\begin{array}{l}\text { Sosialisasi } \\
\text { (sharing) }\end{array}$ & $\begin{array}{l}\text { /communications (pertemuan } \\
\text { tatap muka dan komunikasi }\end{array}$ & $\begin{array}{l}\text { nelectronic dission } \\
\text { igroups, e-mail, telepon, }\end{array}$ \\
\hline & & & langsung) & portal. \\
\hline & & Exchange & $\begin{array}{l}\text { Dokumen, surat-surat, } \\
\text { Presentasi }\end{array}$ & $\begin{array}{l}\text { Web based access to } \\
\text { data, best practices } \\
\text { database. }\end{array}$ \\
\hline \multirow{6}{*}{$\begin{array}{l}\text { Knowledge } \\
\text { Application }\end{array}$} & \multirow{6}{*}{$\begin{array}{l}\text { Knowledge } \\
\text { Application } \\
\text { System }\end{array}$} & & Hubungan $\quad$ langsung & Menangkap dan \\
\hline & & & secara hirarki dalam struktur & mentransfer pengetahuan \\
\hline & & $\begin{array}{l}\text { Direction / alur } \\
\text { pengetahuan }\end{array}$ & informasi yang ada di BPR) & $\begin{array}{l}\text { pemecahan masalah, } \\
\text { sistem penalaran }\end{array}$ \\
\hline & & & & sistem pendukung \\
\hline & & & & keputusan. \\
\hline & & $\begin{array}{l}\text { Routines / } \\
\text { rutinitas } \\
\text { pengeahuan }\end{array}$ & $\begin{array}{l}\text { Kebijakan BPR, praktek } \\
\text { kerja atau uraian tugas } \\
\text { karyawan BPR }\end{array}$ & $\begin{array}{l}\text { Sistem pakar, sistem } \\
\text { perencanaan sumber } \\
\text { daya perusahaan, sistem } \\
\text { informasi manajemen. }\end{array}$ \\
\hline
\end{tabular}

Sumber: Becerra-Fernandez,I dan Sabherwal, R. (2010). Knowledge Management: Systems and Processes. Armonk (N.Y.), London : M.E. Sharpe, p.66).

\subsection{Media dan Mekanisme KM pada BPR.}

Berikut media dan mekanisme manajemen pengetahuan yang penulis kembangkan sesuai dengan kondisi di BPR yang dikutip dari Becerra Fernandez I (2010):

\subsection{Tim Knowledge Management}

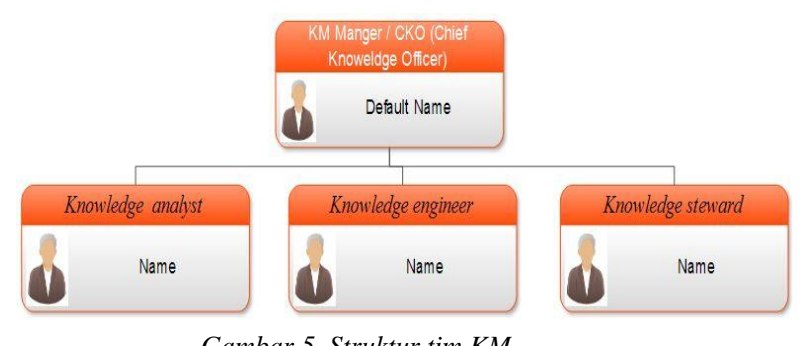


Tim KM berfungsi sebagai fasilitator KM pada BPR. Tim KM akan dipimpin oleh seorang manajer KM dengan beberapa orang yang menjadi anggota tim. Tim dapat dipilih oleh organisasi berdasarkan latar belakang keahlian mereka.

Tabel 3. Jabatan dan Peranan Tim KM

\begin{tabular}{cl}
\hline Jabatan/Posisi & \multicolumn{1}{c}{ Peranan } \\
\hline KM & Bertugas sebagai \\
penanggung jawab, aktif \\
Manager/CKO & mempromosikan agenda KM \\
(Chief Knowledge & dalam dan diluar perusahaan \\
Officer $)$ & memfasilitasi koneksi, \\
& koordinasi dan komunikasi. \\
\hline & Bertugas mengelola isi dan \\
Knowledge & $\begin{array}{l}\text { konten dari KM untuk bisa } \\
\text { disebarkan dan sebagai }\end{array}$ \\
Analyst & administrator KM \\
\hline & $\begin{array}{l}\text { Merupakan seorang software } \\
\text { specialist, bertugas } \\
\text { Knowledge }\end{array}$ \\
merancang dan membangun \\
& infrastruktur KM. \\
\hline Knowledge & Bertugas mengumpulkan, \\
menyimpan dan \\
mendistribusikan knowledge \\
& melalui media KM
\end{tabular}

\subsection{Strategi KM Usulan}

Manajemen pengetahuan merupakan langkah terintegrasi yang membutuhkan strategi dalam penerapan. Kunci sukses pengelolaan pengetahuan tergantung dari kekuatan, tanggung jawab, kepemimpinan dan pembelajaran (Loyd, 1998). Kemudian penulis mengusulkan hal-hal yang harus dilakukan manajemen BPR untuk menjalankan usulan strategi manajemen pengetahuan adalah sebagai berikut:

Kebijakan Pimpinan

- Melaksanakan penghargaan dan sanksi (reward and punishment).

- Training, seminar dan workshop kepada karyawan dan kepala divisi.

- Knowledge management leadership (kepemimpinan berbasis KM)

- Terbentuknya tim KM.

- Melakuan pembaharuan dan peningkatan teknologi informasi untuk mendukung pengembangan KM (mulai dari hardware, software, jaringan internet/intranet dan usernya)

- Kesiapan aplikasi dan web portal KM serta media-media KM.

\section{Membangun Kesadaran dan Tradisi}

Kegiatan yang bisa dilakukan dalam membangun kesadaran dan tradisi berbagi informasi sebagai berikut:

- Seminar dan workshop mengenai knowledge management untuk menambahkan kesadaran pimpinan dan seluruh SDM BPR mengenai pentingnya menajemen pengetahuan sebagai aset berharga.

- Pimpinan dan kepala divisi menyediakan waktu untuk berdiskusi santai dengan para karyawan tentang pengetahuan dan pengalaman.

- Karyawan memahami konsep KM, mulai dari cara menangkap, mengolah, menyimpan dan membagi pengetahuan tersebut serta dampaknya terhadap kemajuan BPR.

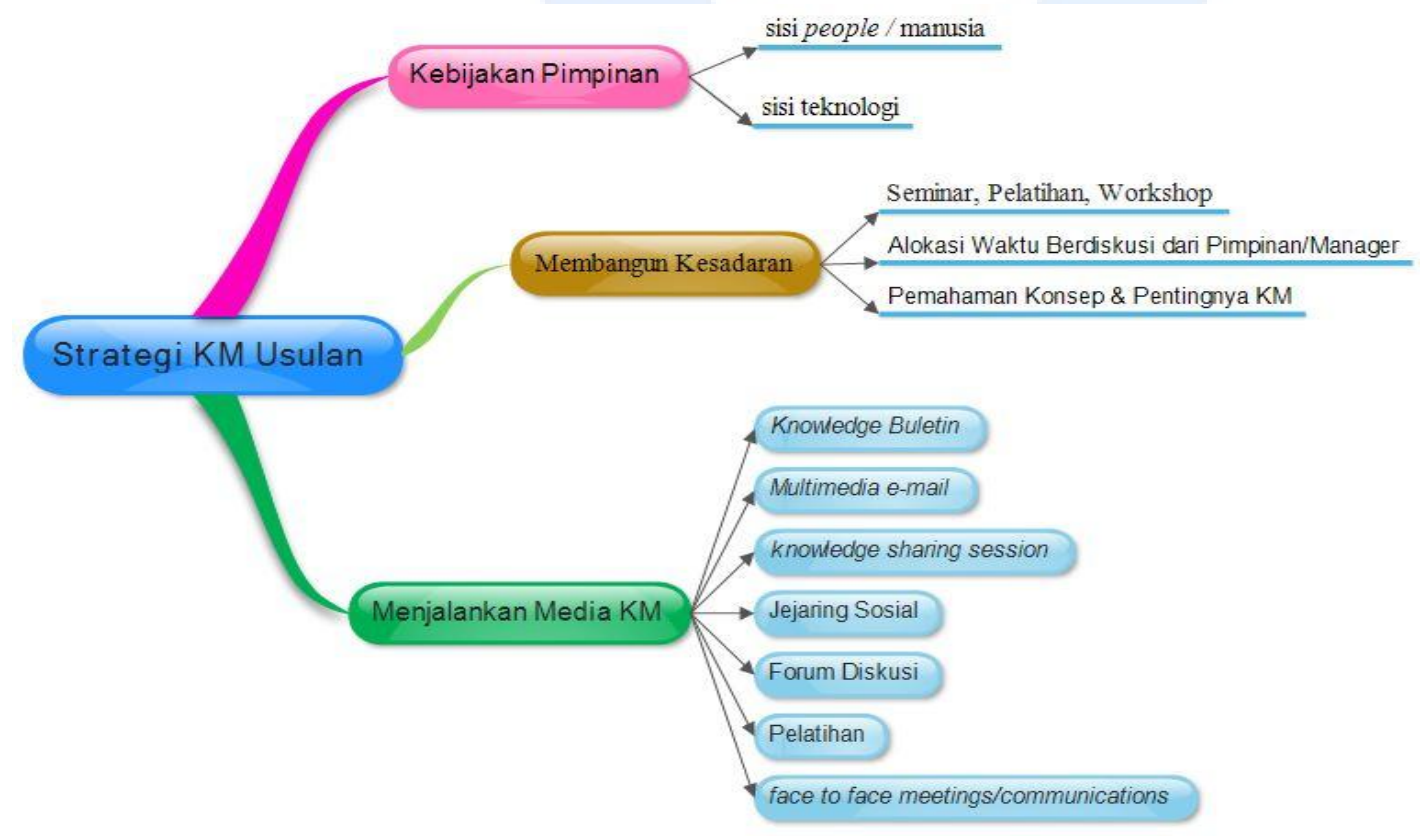

Gambar 6. Strategi KM Usulan 
Menjalankan Media KM Praktis

Proses berjalannya media KM berada dibawah tanggung jawab tim KM yang telah dibentuk atau divisi yang diberi tanggung jawab untuk mengelola KM ini. Dengan kondisi infrastruktur yang bukan TI dan infrastruktur TI yang ada saat ini, BPR bisa menggunakan media KM yang lebih praktis, seperti:

- Knowledge Buletin (buletin pengetahuan).

Buletin ini dapat diterbitkan sebulan atau dua bulan sekali, berisikan update pengetahuanpengetahuan terkini mengenai manajemen/bisnis yang ditekuni oleh BPR.

- Multimedia Email

Email yang isinya variatif, seperti ada gambar, suara/audio, video, penuh warna dan elemen visual lain. Berbeda dengan email tradisional yang kontennya sedikit membosankan.

- Knowledge Sharing Session (berbagi pengetahuan).

Selama sekitar 1-2 jam, setidaknya setiap satu/dua bulan sekali. Bisa dilakukan dengan mengundang narasumber dari luar atau internal, dipandu oleh seorang medorator dan dihadiri oleh pimpinan BPR atau kepala divisi. Hasil sharing session ini kemudian juga bisa diupload ke portal pengetahuan atau grup jejaring sosial yang dimiliki BPR, sehingga setiap karyawan bisa mengakses materi.

- Social Networking (jejaring sosial).

Para karyawan ditempat mereka bekerja sulit untuk menghindari/tidak mengakses media ini. Situasi seperti ini mestinya mampu dimanfaatkan oleh BPR untuk menggunakan jejaring sosial sebagai media berbagi pengetahuan. BPR membuat grup yang difungsikan untuk meningkatkan pengetahuan karyawan, menambah wawasan setiap hari, mendiskusikan banyak hal dan bertanya tentang pemecahan kasus-kasus yang dialami.

- Forum Diskusi

Setelah karyawan menemukan permasalahan baru beserta solusinya atau mendapatkan pengetahuan baru, langkah selanjutnya adalah mengajak karyawan lain untuk mendiskusikan tentang temuan baru tersebut. Forum diskusi juga terdiri dari seorang moderator, notulen dan narasumber baik dari internal atau eksternal BPR.

- Pendidikan, Pelatihan, Seminar dan Workshop Mengadakan pelatihan, seminar, workshop secara berkala, satu atau tiga bulan sekali untuk pengembangan pendidikan dan potensi karyawan BPR dan menambah pengetahuan baru sesuai dengan kebutuhan dan perkembangan ilmu pengetahuan tentang perkreditan.

- Face to Face Meeting (komunikasi langsung). Pertemuan yang dihadiri hanya beberapa orang saja dan dilakukan secara langsung, karyawan yang lebih berpengetahuan dan berpengalaman berbagi pengetahuan yang dia miliki kepada karyawan lainnyang masih baru atau dengan karyawan yang sudah lama yang sebagai lawan bicara pada saat itu.

\section{KESIMPULAN DAN SARAN}

Penelitian ini menggunakan beberapa metode yakni framework roadmap Amrit Tiwana, model Zack untuk analisis kesenjangan pengetahuan karyawan dan strategi perusahaan, serta menggunakan model SECI Nonaka dan Takeuchi dalam siklus manajemen dan penciptaan pengetahuan. KM memfasilitasi proses terjadinya siklus dan mekanisme bagi perusahaan agar bagaimana aset-aset yang ada mampu dipertahankan dan dikembangkan untuk mendukung nilai bisnis perusahaan tersebut secara efisien dan efektif. Dengan demikian, diketahui bahwa teknologi hanyalah sebuah alat dan KM membutuhkan teknologi untuk efektivitas prakteknya.

Berdasarkan analisis dan pembahasan strategi manajemen pengetahuan BPR, dirasa perlunya penerapan manajemen pengetahuan pada BPR untuk menangkap, mengelola, menyimpan, membagi, mempertahankan dan terus mengembangakan aset pengetahuan serta pengalaman yang dimiliki karyawan.

Adapun yang dapat penulis simpulkan yaitu:

- Terdapat tujuh pengetahuan yang diharapkan BPR untuk dimiliki karyawan marketing, namun tidak semua pengetahuan tersebut dimiliki oleh karyawan. Hasil kesenjangan pengetahuan tertinggi adalah knowledge funding dan lending (pengetahuan pencarian dan pencairan dana) serta knowledge surveyor (kemampuan melakukan survei lapangan), sementara kesenjangan pengetahuan terendah adalah knowledge management costumer (pengetahuan manajamen data nasabah).

- Aset pengetahuan BPR secara umum terdapat pada struktur BPR, operasi fungsional BPR dan prilaku/kebiasaan BPR. Dimana setiap knowledge yang telah teridentifikasi terbagi ke tacit knowledge dan explicit knowledge.

- Belum ada tim, divisi serta agenda khusus dalam uraian tugas BPR untuk mengelola aset pengetahuan BPR.

- Tersedia infrastruktur jaringan internet/intranet pada BPR yang bisa difungsikan untuk program KM.

Saran yang diberikan, seperti:

- Strategi KM yang dirancang harus mendapat dukungan penuh dari top manajemen.

- BPR menempatkan tim KM pada struktur organisas agar tugas dan tanggung jawab 
pengelola pengetahauan menjadi jelas dan terarah.

- Untuk penelitian lebih lanjut dapat melakukan pengembangan infrastruktur TI yaitu knowledge management system (sistem manajemen pengetahuan) pada BPR dan menuntaskan seluruh langkah yang ada pada metode Amrit Tiwana.

\section{DAFTAR RUJUKAN}

Honeycutt, J. 2005. Knowledge management strategies. Jakarta: PT. Elex Media Komputindo.

Kurniawan, Inyoman R. 2010. Perancangan Knowledge Management System di SMKN 1 Kotabaru (Studi Kasus Kegiatan Belajar Mengajar Bahasa Inggris) menggunakan framework 10 langkah Amrit Tiwana. Kalimantan Selatan.

Nonaka I, Toyama R. 2007. Strategic Management as Distributed Practical wisdom (Phronesis). Industrial and Corporate Change.

Nonaka I, Konno N. 1998. The Concept of BA: Building A Fondat ion for Knowledge Creation. California Management Review. 40(3), pp.40-55.

Nonaka I, Toyama R. 2005. The Theory of The Synthesis. Industrial and Corporate Change. 14(3), pp.419-436.

Nonaka, I., \& Peltokorpi, V. 2006. Objectivity and subjectivity in knowledge management: A review of 20 top articles. Knowledge and Process Management, 13(2), pp.73-82.

Nonaka, Ikijiro dan Takeuchi, Hirotaka. 2005. The knowledge creating company: how Japanese Companies create the dynmics of innovation. New York. Oxford University Press.
Prijono K. 2008. Perancangan Knowledge Management (KM) Readiness Tool. eIndonesia Initiatif. 21-23 Mei 2008. Konferensi dan Temu Nasional Teknologi Informasi dan Komunikasi untuk Indonesia.

Sangkala. 2007. Knowledge Management: suatu pengantar memahami bagaiman organisasi mengelola pengetahuan sehingga menjadi organisasi yang unggul. PT. Raja Grafindo Persada Jakarta.

Setiarso, Bambang dkk. 2009. Penerapan Knowledge Management pada Organisasi. Graha Ilmu, Yogyakarta.

Situmorang, S.H. 2008. Analisis Data Penelitian Menggunakan Program SPSS. USU Press, Medan.

Tim Penulis. Buku Profil BPR. 2012. Bagian Umum. PT. Bank Perkreditan Rakyat Tuah Negeri Mandiri Pekanbaru.

Tiwana, Amrit. 1999. The Knowledge Management Toolkit. 1999. Prentice Hall.

Tobing, Paul L. 2007. Knowledge Management: Konsep, Arsitektur dan Implementasi”. Graha Ilmu, Yogyakarta.

Von Krogh, G., Nonaka, I., \& Aben, M. 2001. Making the most of your company's knowledge: A strategic framework. Long Range Planning. 34(4), pp.421.439.

Yuliazmi. 2005. Penerapan Knowledge Management pada Perusahaan Reasuransi: Studi Kasus PT Reasuransi Nasional Indonesia. Tesis. Jakarta. Magister Ilmu Komputer. Universitas Budi Luhur.

Yusup, Pawit M. 2012. Perspektif Manajemen Pengetahuan, Informasi, Komunikasi, Pendidikan, dan Perpustakaan. Edisi 1. Jakarta: Rajawali Pers.

Zack, M. 1999. Developing a knowledge strategy. California Management Review, 41, pp.125-145. 